\title{
Combination of needle-knife and hemostatic forceps in a novel hybrid knife (Blossom-knife) improves endoscopic submucosal dissection in porcine model
}

As a widely used treatment of early gastrointestinal neoplasms, endoscopic submucosal dissection (ESD) requires specifically designed surgical instruments, primarily an endoknife for dissection and hemostatic forceps for hemostasis [1]. Because switchover of different instruments makes ESD challenging in terms of skills, as well as time-consuming [2-4], there is an urgent need to develop hybrid instruments that can be used to perform ESD more safely and easily [5]. Here we report on the use of our newly invented hybrid knife (Blossom-knife), which perfectly integrates a needle-knife and he- mostatic forceps ( $\mathbf{F i g . 1}$ ), to achieve effective hemostasis and reliable dissection during ESD in a porcine model ( Video 1).

The multiple functions of the Blossomknife were tested in a 40-kg pig. It was found that, using needle-knife mode, the Blossom-knife was able to both beautifully mark the thin mucosa of the esophagus ( $\triangleright$ Fig. $\mathbf{2 a}$ ) and smoothly incise the thick mucosa of the stomach ( Fig.2b). Meanwhile, the hemostatic forceps mode performed outstandingly in stopping bleeding from an arteriole in the stomach ( $\triangleright$ Fig. 2 c). As stable design functions were confirmed, the Blossomknife was used to perform a complete ESD in the rectum. After saline solution was injected into the submucosal layer, mucosal incision and submucosal dissection were conducted using the needleknife mode ( $\mathbf{F i g . 2} \mathbf{d}$ ). When intraoperative hemorrhage and suspected vessels were encountered, instead of changing instruments, the needle-knife mode could be directly converted to the hemostatic forceps mode to control the bleeding quickly and accurately. The en bloc resection of a $2 \times 4-\mathrm{cm}$ piece of mucosa ( Fig. 2e) was achieved within 20 min-
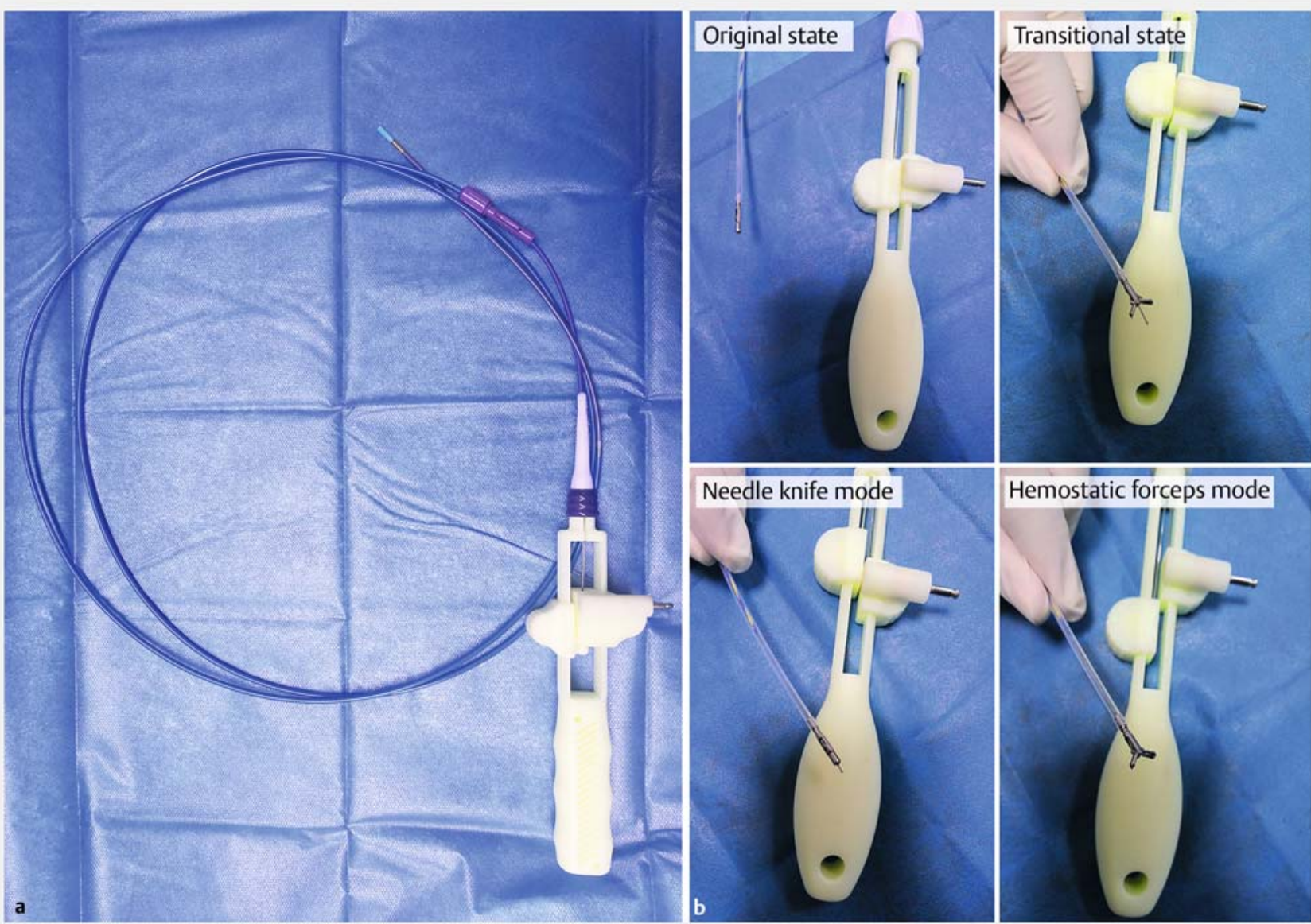

Fig. 1 Photographs of the new Blossom-knife showing: a the appearance of the whole tool; $\mathbf{b}$ maneuvering of the handle of the Blossom-knife to switch between the needle-knife and hemostatic modes. 

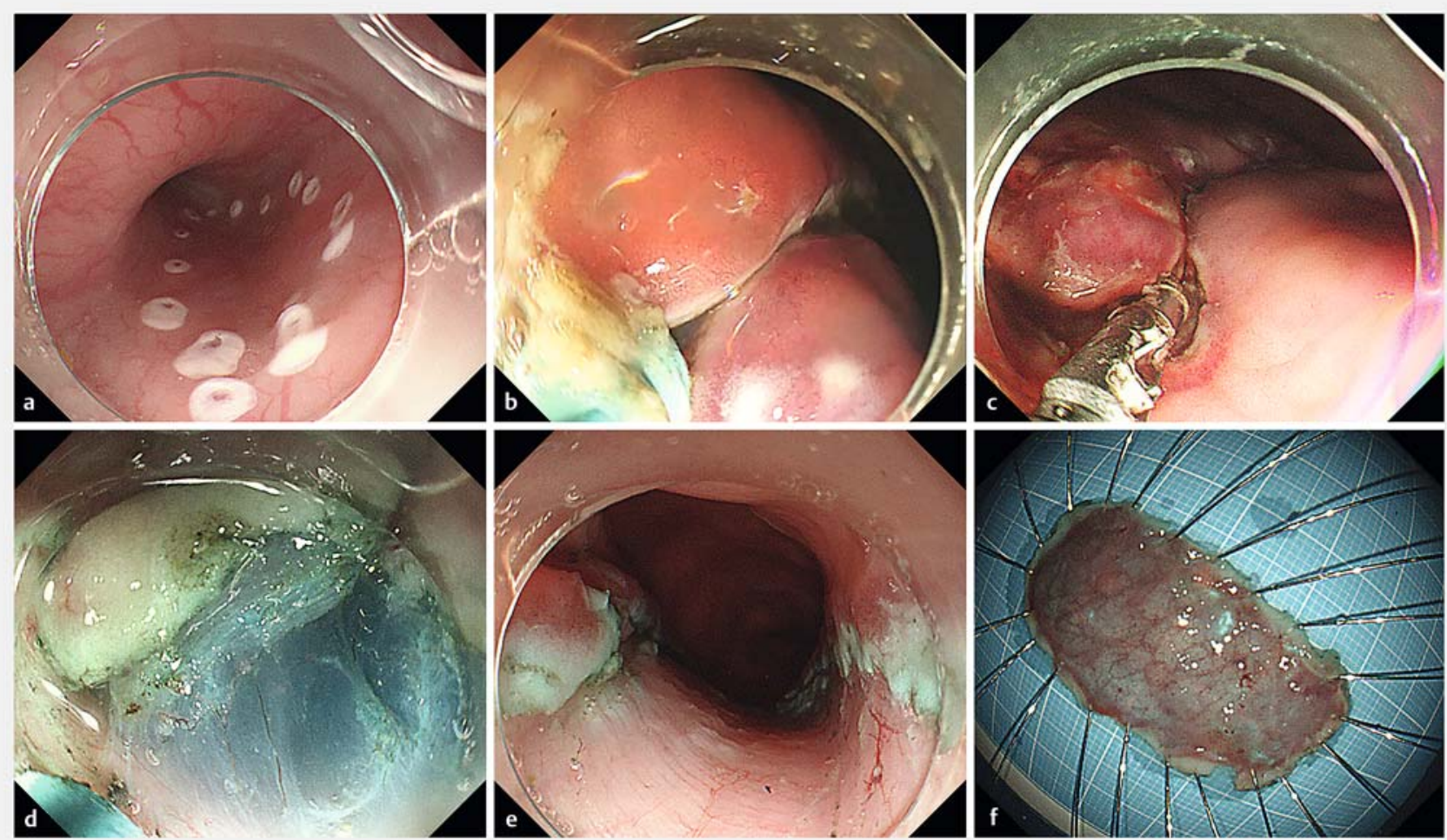

- Fig. 2 Images of the use of the novel Blossom-knife to perform endoscopic submucosal dissection in a porcine model showing: a smooth marking on the thin mucosa of the esophagus using needle-knife mode; $\mathbf{b}$ steady incision of the thick mucosa in the stomach using needle-knife mode; $\mathbf{c}$ reliable hemostasis of an arteriole in the stomach using hemostatic forceps mode; $\mathbf{d}$ mucosal incision and submucosal dissection being easily and safely performed in the rectum using needle-knife mode; $\mathbf{e}$ a beautiful mucosal defect after rectal ESD was completed within 20 minutes; $f$ the en bloc resected specimen, which measured about $2 \times 4 \mathrm{~cm}$.

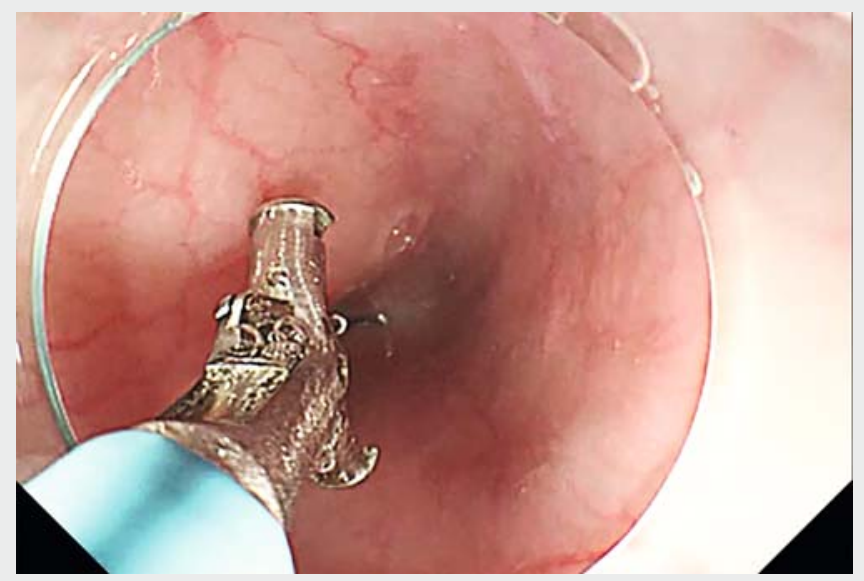

$\checkmark$ Video 1 Use of a new combined needle-knife and hemostatic forceps (Blossom-knife) for endoscopic submucosal dissection (ESD) in a porcine model showing: maneuvering of the handle to transform between needle-knife mode and hemostatic mode; confirmation of the successful functioning of the device in both modes; complete ESD being performed in the rectum of a young pig. utes, without any perforation occurring ( Fig. 2f).

In this study, the newly developed dissection and coagulation-fused Blossomknife was shown to perform margin marking, circumferential incision, submucosal dissection, and vascular coagulation during the different steps of the ESD procedure. This new device makes ESD much easier and safer, and potentially faster, meaning that ESD will be more amenable for endoscopists.

Endoscopy_UCTN_Code_TTT_1AQ_2AD

\section{Competing interests}

The authors declare that they have no conflict of interest. 
Xiao Hu, Sheng-xi Han, Wei-hui Liu Department of Gastroenterology and Hepatology, Sichuan Academy of Medical Sciences \& Sichuan Provincial People's Hospital, and School of Medicine, University of Electronic Science and Technology of China, Sichuan Province, China

\section{Corresponding author}

\section{Wei-hui Liu, MD, PhD}

Department of Gastroenterology and Hepatology, Sichuan Academy of Medical Sciences \& Sichuan Provincial People's Hospital, Chengdu, Sichuan Province, 610072, China audiliu12@163.com
[1] Kuwai T, Yamaguchi T, Imagawa $\mathrm{H}$ et al. Endoscopic submucosal dissection of early colorectal neoplasms with a monopolar scissor-type knife: short- to long-term outcomes. Endoscopy 2017; 49: 913-918

[2] Takeuchi Y, Uedo N, Ishihara R et al. Efficacy of an endo-knife with a water-jet function (Flushknife) for endoscopic submucosal dissection of superficial colorectal neoplasms. Am J Gastroenterol 2010; 105: 314-322

[3] Fernandez-Esparrach G, Matthes EL, Maurice $D$ et al. A novel device for endoscopic submucosal dissection that combines water-jet submucosal hydrodissection and elevation with electrocautery: initial experience in a porcine model. Gastrointest Endosc 2010; 71: 615-618

[4] Tanaka S, Toyonaga T, Morita Y et al. Efficacy of a new hemostatic forceps during gastric endoscopic submucosal dissection: A prospective randomized controlled trial. J Gastroenterol Hepatol 2017; 32: 846-851

[5] Ciocirlan M, Pioche M, Lepilliez V et al. The ENKI-2 water-jet system versus Dual Knife for endoscopic submucosal dissection of colorectal lesions: a randomized comparative animal study. Endoscopy 2014; 46: 139143
Bibliography

Endoscopy 2021; 53: E169-E171

DOI 10.1055/a-1226-6347

ISSN $0013-726 \mathrm{X}$

published online 20.8.2020

(c) 2020. Thieme. All rights reserved.

Georg Thieme Verlag KG, Rüdigerstraße 14, 70469 Stuttgart, Germany

\section{ENDOSCOPY E-VIDEOS}

https://eref.thieme.de/e-videos

回回 Endoscopy E-Videos is a free access online section, reporting 靣: on interesting cases and new techniques in gastroenterological endoscopy. All papers include a high quality video and all contributions are freely accessible online.

This section has its own submission website at

https://mc.manuscriptcentral.com/e-videos 